\title{
The World and the Limits of Language: The \\ Philosopher's Concern with Language and \\ Communication of Meaning
}

\author{
Ifechukwu J. Ndianefoo* \\ DOI: http://dx.doi.org/10.4314/ujah.v12i2.8
}

\section{Introduction}

The philosopher's central concern since the formal beginning of philosophy with Thales in the $6^{\text {th }}$ century B.C can be separated into the first-order and the second-order. The firstorder concern is the quest to understand the world while the second-order concern is clarification of thought or conceptual analysis as the analytic school is wont to call it.

The two concerns are interdependent but in the 1950s and 1960s conceptual analysis dominated and came to be regarded by most people within and outside the discipline as the defining characteristic of philosophy because, according to them, the new sciences have taken over the task of understanding the world from philosophy. However, after the baleful effects of two world wars, the intensification of religious and ethnic bigotry, and ever narrowing labyrinth of science, the first-order concern of philosophy is coming into favour again. The need to understand the totality of existence as a dynamic unity and the implications thereof for man has been renewed.

This essay is written in the view that the first-order and the second-order concerns of philosophy are ever interdependent. This accounts for tracing the analytic thread from pre-Socratics in the $6^{\text {th }}$ century B.C to the contemporary time and arguing implicitly and explicitly that the first-order concern has enriched the second-order concern by evolution and expansion of concepts which in turn have not only 
expanded our understanding of what there is (truth) but also how we communicate this truth meaningfully.

That task of understanding the world cannot begin to get off the ground without logical clarification of thought, language and meaning. On the other hand, logical clarification of thought, language and meaning is driven by the object of understanding the world.

The paper concludes that the first and second order concerns of philosophy inexorably generate a people's culture which in turn determines a people's social praxis. In this way, the mistaken belief held by many uninformed people that philosophy is an impractical and irrelevant armchair nit- picking is once again proven wrong.

\section{The Nature and Object of Philosophy}

Philosophy, like other disciplines in the humanities and social sciences, is not susceptible to a universal definition. This means that there is no generally accepted definition of philosophy. This regrettable "Babel" in the conceptualization and definition of philosophy is a function of the fact that the obvious peculiarities of one's spiritual, psychological, and material backgrounds and circumstances determine one's characterization of philosophy. The following are some of the more popular but divergent characterizations or definitions of philosophy.

Etymologically, philosophy is defined as love of wisdom. According to James Christian in his book, Philosophy: An Introduction to the Art of Wondering, the germ of philosophy as such is curiosity and wonder. In his words:

"To philosophize is to wonder about life-about right and wrong, love and loneliness, war and death. It is to wonder creatively about freedom, truth, beauty, time and thousand other things" (Christian, 2003:1). 
For the British philosophy and mathematician, Bertrand Russell, philosophy is a critical and rigorous intellectual activity, a no man's land between science and religion. The Ghanaian philosopher, Kwasi Wiredu, conceives philosophy as concerned with the intellectual foundations of our life, interrogating and evaluating the foundations of our beliefs and actions. (Wiredu, 1995: 5). Philosophy is also seen as a mega -science of sorts in the following words:
"Philosophy, as a cleaner laboratory, as a searchlight, as a virus detector and facilitator, critically assesses every object of experience and intuition in space and time through its four branches, namely, metaphysics, epistemology, logic and ethics" (Dukor, 2005:364).

\section{Thought, Language and Communication of Meaning}

The three terms of the sub-title are inextricably intertwined. Thought as denotation of consciousness can only be communicated in a language. I leave out the larger and contentious issues of whether an individual can think other than in a language. It would seem that thought, language and communication of meaning constitute an ineluctable trinity in human rationality.

In taking an analytical approach to this trinity, we see that thought as such denotes consciousness. Language, on its own, is an arbitrary human invention but which once made sticks. An expert definition of language is taken from Edgar Sturtevant who conceives it as ":a system of arbitrary vocal symbols by which members of a social group cooperate and interact" (Ijoma, 1988:47). The obvious shortcoming of Sturtevant's definition of language is that it does not 
accommodate the private language thesis which posits that a person can formulate and use private symbols of meaning.

Language may be articulate or inarticulate expression of thought and may assume the form of a system of symbols or gestures aimed at conveying meaning. Language, therefore, does the primary function of externalizing and objectifying thought processes. Nonetheless, the secondary functions of language are no less significant. These are stimulative, descriptive and argumentative functions (Popper, 1963:295).

A people develop a language appropriate to their needs and environment. Such a language serves them as a medium for communication, the transmission of knowledge, culture and values, and for the articulation of their worldview. In this regard, various languages can be said to be equal in so far as each serves adequately the fundamental language needs of its linguistic group.

A language is a living socio-cultural phenomenon which grows and develops into other forms and may even die out altogether like the Latin language which is considered as "a dead language", its body and tissues having atrophied and fossilized into the bodies of French, Spanish, Italian, Portuguese, English, etc. In contact with another language or culture, a language can, through the process of borrowing or imitation, enrich both its vocabulary and structures to cope with new realities; hence the appearance of new words, and new forms of expressions in a language, either borrowed from another language or coined from existing ones in the language.

\section{Philosophy as a Tool for Clarification of Thought and Language}

Philosophy in its pristine mandate as a mega discipline and intellectual clearing -house for all the physical, intellectual 
and spiritual products of our civilization engages and subjects all these cultural forms to rational scrutiny. The aim of philosophy in such a gargantuan task has been to synthesize all of human experience to generate a rational structure of reality, to furnish a meaningful close-knit universe and banish a shambolic multiverse. Philosophy carries out its sacred mandate through the instrumentality of its logical, analytical, critical, reflective, contemplative, pragmatic and hermeneutical methods.

Undoubtedly, our thoughts and language, our whole communication process, cannot shield itself from the searchlight of philosophy. Although the above methods of philosophy are inextricably interwoven in any philosophical quarrying on human experience, it seems incontrovertible that the logical and analytical methods are preeminent in rational clarification of thought and language in the communication art.

If it is maintained as it is unequivocally the case that clarity of thought and language are critical cultural requirements which our rational nature stipulates, then the bounden duty of philosophy as the clarifier and purifier of our thought and language in the communication process assumes an urgent character.

The profound but devious nature of human thought is well recognized in antiquity in the query of Jeremiah in the bible: "who can understand the human heart? There is nothing else so deceitful, it is too sick to be healed. (Jeremiah 17:9). Sages and modern scholars have continued to ponder and speculate on the profundity and plasticity of human thought because of their unmistakable intuition that human thought is central to the cultivation of attitude, behavior and the general social culture.

It is the fundamental role that thought plays in the attitudinal and behavioral patterns of the individual and, by 
necessary implication, in his society that has made philosophical clarification and purification of our thought a desiderata. It is therefore not fortuitous that philosophers right from the ancient through the modern to the contemporary epochs have postulated one method or the other for the clarification and training of thought towards the good.

For Socrates (470-399 B.C), the clarification and training of thought toward the good was a supreme task. He set himself to accomplish this task by systematic questioning, in the course of which he not only cleared his opponent's mind of much muddles and misconceptions but developed his own two important contributions to logic, namely, induction and general definition (Plato, 1954:10).

The critical interrogation and training of human thought inaugurated by Socratic intellectual midwifery has continued to be improved upon by subsequent philosophers. The German turned British philosopher, Karl Raimond Popper postulated, in his falsificationist method, that human thought and knowledge grow by an unending feedback process of criticism. Popper adored the pre-Socratic and early post-Socratic philosophers of Ancient Greece for pioneering what he called their revolution in the history of thought, namely, their institutionalization of criticism. The preSocratics and early post-Socratics encouraged their pupils to discuss, debate, criticize and to produce a better argument or theory if they could. Such, according to Popper, were the historical beginnings of rationality and scientific method and they were directly responsible for that galloping growth of human thought that characterizes not only ancient Greece but the whole western culture that has seen itself, since the Renaissance, as the legatee of the ancient world (Popper, 1963:151). 
While Popper waxed as the most vocal and articulate advocate of the critical interrogation and training of human thought in the twentieth century, his country man, Ludwig Wittgenstein's philosophy became the fiery manifesto and rallying point of a large and eminent circle of philosophers who saw the logical analysis of our thoughts and concepts (symbols) as the raison d'être of philosophy. The analysts, as these philosophers came to be known, held that thought and language are inseparable and, therefore, that the logical analysis of one would yield the analysis of the other. Such analysis, they believe, would dissolve (if it cannot resolve) the philosophical problem at issue. The analysts progressively came to hold that in order to clarify and train our thought (concepts) all that needs be done is laying rules of meaningful linguistic usage. For example, under what circumstances would it be linguistically meaningful to say so and so or the reverse, to think so and so? The salutary and much desired result of this legislation of linguistic meaning is the containment of speculative and fantastic thought.

The powerful silent effect of philosophy on human thought and, ipso facto, on human action is tepidly and parsimoniously articulated by Bertrand Russell in the famous and memorable quote: "The circumstances of men's lives determine their philosophy but their philosophies do very much more to determine their circumstances". (1956:15). In another breadth, the illustrious philosopher wrote that philosophic contemplation "enlarges not only the objects of our thoughts, but also the objects of our actions and our affections: it makes us citizens of the universe, not only of one walled city at war with all the rest. In this citizenship of the universe consists man's true freedom and his liberation from the thralldom of narrow hopes and fears" (1912:93).

The merits of clarified and trained thought which philosophy bestows on its votary are invaluable and these 
merits have brought to philosophy the ire of the dogmatic and the dictatorial. The murder of the gadfly of Greek civilization, Socrates, by the Athenian State stands as the first original sin against philosophy. The same animus against philosophy's civilizing credentials drove Emperor Domitian to banish philosophers from Italy in 90 A.D.

If we sustain the axiomatic thesis developed above that philosophy interrogates, trains and clarifies human thought and couple the thesis with the linguistic fact that our thought can only be expressed and communicated in language, we arrive at the truth that philosophy as it seeks to clarify thought also seeks to clarify language as the medium of publicizing and communicating thought.

Philosophy, in its analytic method championed by Ludwig Wittgenstein and logical positivists, seeks to clarify language with a view to showing how words mean and how they relate to the world. In this regard, philosophy takes critical interest in the proper use of words, their having proper reference, sense, meaning and, therefore, their efficacy in communicating the truth.

Philosophy's concern with language and communication of the truth, whatever that may be, is as old as philosophy itself. The differences amongst the earliest philosophers, the Ionians in their cosmological speculations were largely a question of the proper use of words and naming which resulted in their different conceptions about the original stuff of the world. It is this understanding of the delicate dynamics of thinking, naming and conceptualization which led subsequent philosophers to mount some rigorous attempts at training, clarifying and purifying our use of words and concepts and hence burnish meaningless and misleading verbalism in our language and communication.

In western thought, the first systematic attempt at such linguistic and communicative clarity began with the 
inimitable philosopher, Socrates. He was concerned with the proper meaning and use of words. His dialectics was chiefly concerned with the analysis of words, the delineation of the implicit and explicit meanings. The whole aim was to point to the abuse and the ignorance of the users of words. With his then revolutionary doctrines of deduction and general definition, Socrates analyzed and clarified such concepts as piety, justice, knowledge, temperance etc.

The critical and analytic tradition in discourse pioneered by Socrates was continued, however in a tendentious way by medieval philosophers. The Medieval philosophers conducted linguistic analysis only to clip the wings of earlier secular philosophies and hence secure adequate intellectual space to postulate and advocate theological beliefs. The medieval thinkers or schoolmen, as they are styled, reveled in flamboyant and esoteric play with words. This is why Medieval tendentious and prejudiced philosophizing is ill-reputed as period of linguistic corruption and bastardization (Ozumba, 2004:10).

Francis Bacon (156-1626) was destined to redirect and focus philosophy's training and clarification of language and communication from the medieval prejudiced and tendentious logico-linguistic analysis into a presuppositionless and secular philosophic-linguistic analysis. Bacon pejoratively termed the medieval misleading and tendentious use and analysis of words to rationalize the Christian faith "idols" or "false divinities". These are idols of the cave, of the tribe, of the market place and of the theatre. These idols, Bacon rightly maintained, have their roots in certain linguistic malapropisms and abuses and should therefore be exploded by free, presuppositionless, unprejudiced secular logico-linguistic analysis.

The challenges thrown up by Bacon's disavowal of medieval linguistic obfuscation or "distempers of learning" as 
he called it, was taken up by a fellow Englishman, John Locke, (better known for his theory of Social Contract). In his book, Essay Concerning Human Understanding (1990), Locke articulated a far-reaching and ramified theory of logico-linguistic analysis geared towards efficient language and communication. In his logico-linguistic analysis, Locke dwells on words, formation of sentences, general terms, names (naming), abstract general names (abstraction), linguistic representation and references. He defends the necessity of abstract terms as a way of adhocly ending an otherwise interminable possibility of naming. General names, in philosophico-linguistic analysis are general terms made to stand for class objects instead of insisting on naming every single object. For Lockean logico-linguistic analysis, language is what distinguishes man from brutes. Man is blessed with special mental endowment which enables him to form words and sentences of complete nature. Locke's analysis explains why and how words have come to be linked to ideas as channels for communication of meaning. Locke's empiricism employs the method of linking the seen with ideas via names (word). What you see create ideas and to be able to identify and re-identify the ideas, names were invented to help us distinguish among things. Locke's logicolinguistic analysis is termed "a physicalistic ideational theory of language". (2004:126). This simply means that physical objects which we get to perceive via our sensory organs generates ideas or pictures of themselves in us which we develop language (or communicative symbols) to communicate to others and thus make social life possible.

Philosophical clarification of thought and language in aid of communication of meaning peaked in the contemporary period $\left(20^{\text {th }}\right.$ century) in the philosophies of logical positivism, old and new Wittgenstein and Bertrand Russell's logical atomism collectively called British analytic 
philosophy. Of course, the British analytic tradition had its echoes in American philosophical thought where Charles Sanders Peirce and William James were the torch-bearers.

British analytic philosophy was much engrossed with language and communication of meaning that it came to be known alternatively as linguistic philosophy. The motivation of the analysts' concern with meaningful and the meaningless in language was their grave suspicion against the metaphysicians' claim to a holistic knowledge of the origin, structure and dynamics of the world. The analysts held that philosophical problems are more or less linguistic, that is, they arose from misuse of words and concepts in our language. Thus, the analysts' absorption with meaning, sense, and reference as communicated in language. Wittgenstein's dictum on language use "whereof thou cannot speak thereof keep shut" became the analysts' article of faith.

In this light, the analysts sought to anatomize language and express its controversial potentials. Just as a cardiologist needs to know about the heart to be able to handle a heart problem, even so is knowledge of the structure and anatomy of language necessary to the analytic philosopher to be able to handle problems that affect language in communicating meaning.

The analysts' mandate to analyze and clarify language and understand the world (as mediated through language) has stratified into two streams of thought, namely, the ordinary language analysis and ideal language analysis. The ordinary language analysis (pioneered by Berkeley, Richard Ryle and John Austin) insists on a return to the ordinary meaning of words and concepts undistorted by technical obfuscations of the various disciplinary usages. The pioneer of ordinary language analysts, Berkeley had held that: 
the illiterate bulk of mankind that walk the high road of plain common sense are for the most part unperturbed by the disquisitions, polemics, disagreements and confusions of men of letters or philosophers who complicate simple matter through esoteric and rarefied use of languages. (Ozumba, 2004:112).

In the ordinary use of words, concepts and sentences, speakers of a language, say English, understand themselves when one person says "the cat is in the bag", the hearer understands that the speaker is talking about "cat" and "bag" and the preposition "in"; but a philosophical or technical question may impute to this ordinary language some air of complication by asking what do you mean by cat? Is that actually a bag or a similitude of a bag? This reminds one of the hairs splitting between idealism and materialism. The idealist says the table I am seeing is nothing but an idea in the mind, while the materialist says the table is something concrete and physical. We see such controversies over names, concepts, words, sentences and what they are supposed to mean. This is so often because of the deviation from the ordinary and plainly cognizable acceptance of words, sentences and names. A similar misconceptions and misuse of words leading to a thicket of linguistic and conceptual puzzles and confusions arise over our ideas about "mind" and "Body". The mind was regarded as something that exists independently of the body, as an immaterial entity that inhabited the body and operated from inside, like someone driving a car. Gilbert Ryle in his book, The Concept of Mind, dismissed this view as erroneous and product of conceptual and linguistic abuse. On the basis of extensive linguistic and conceptual analyses, which comprise the book, Ryle argues that what we humans do is to categorize certain 
aspects of our own behavior and experience as mental and then attribute them to different subject from the rest and then reify that subject as mind. He holds that careful investigation of our use of mental concepts shows that we do not have justification for doing this, indeed that the human being is an entity, one subject of behavior and experience, with a single identity and single history. By such reification, Ryle maintains we have made what he calls "category mistake". We treat the concept of mind as if it designated one sort of thing where in fact it designates a quite different sort of thing. We think of mind as separately existing entity that does things and has experiences, when all the time it is merely an umbrella term for certain of our various modes of behaviorperformance, disposition, experience and so on - all of which should correctly be attributed to a single subject. This category mistake, Ryle rightly maintained, breeds a whole population of other mistake in our assumptions about us. It is a prime example of a pseudo-philosophical problem stemming from conceptual and linguistic puzzles and confusions which painstaking conceptual and linguistic analyses can dissolve.

To protect our ordinary language use from such conceptual and linguistic puzzles and confusions, philosophers like Ryle, P.F Strawson and J.L Austin abjure such out-of-the-way and esoteric use of words as seen in philosophical obfuscations, abstract notations and poetics. Ironically, the desire to find a lasting solution to the problem of ambiguity , vagueness and imprecision in our communication of linguistic or literal meaning which drove ordinary language analysts to abjure linguistic esotericism and obfuscations turned a group of philosophers in the direction that frowned at ordinary language use and longed after an ideal language. 
Ideal language analysts include Bertrand Russell, Rudolf Carnap, Ludwig Wittgenstein and Leibniz. These logico-linguistic analysts hold that ordinary language is inadequate for depicting reality, most especially for philosophical and scientific discourse. This, for them, is so because of its vagueness, ambiguity, context-dependence, and inexplicitness. This group of logico-linguistic analysts sees, as their task, that of constructing a logically perfect language that will capture the structure of reality, that would picture the world rightly in the pattern of correspondence of words with things in the world or state of affairs. Ideal language, in their construal therefore, is language that is perfect and adequate in communicating ideas, thoughts and objects in the clearest way devoid of the ambiguity, imprecision, indiscreetness and unclarity that characterize ordinary language. The ideal language analysts sought to overcome the short comings of ordinary language by various logicolinguistic and conceptual analyses. We will briefly discuss these analyses as logico-linguistic models geared towards attaining greater efficiency in the communication of meaning.

Rudolf Carnap in his book, The Logical Syntax of Language (1937) laid out logico-linguistic calculus that would take care of the problems or inadequacies of ordinarily language. He sought to device a linguistic calculus that would appropriate the exactitude of the language of mathematics. Also in his other book, Logical Structure of the World (1967), Carnap attempts a logical and linguistic reconstruction whereby new definitions are given for old concepts. Here, the formulation is deliberate and the new definitions are expected to be superior to the old in clarity and exactness and, above all, should fit into a systematic structure of concepts.

For Russell, logic and mathematics provided both a springboard and vision towards the invention of his theory of 
ideal language. Russell thought that since it was possible to construct a logic by which the whole of mathematics could be derived from a small number of logical axioms as he had already done with A.N. Whitehead in their Principia Mathematica, then why could not this logic form the basis of a language that could accurately communicate everything that could be stated (Stumpf, 1977:433-4). Russell's assumption was that the world of facts would correspond to his specially constructed logical language. The vocabulary of the new logic would, for the most part, correspond to particular objects in the world. Summarily, language, according to Russell, consists of a unique arrangement of words, and the meaningfulness of language is determined by the accuracy with which these words represent facts. Words, in turn, are formulated into propositions. Thus he concludes that "in a logically perfect language, the words in a proposition would correspond one-by-one with the components of the corresponding facts" (Stumpf, 1977:434).

This line of ideal language was further developed in Wittgenstein's Tractatus-Logico-philosophicus where he deals with the principles of symbolism and the relations which are necessary between words and things in language. For Wittgenstein, the logical structure of language corresponds with the logical structure of the world. He postulated a picture theory of language. The idea was to construct ideal language that would picture the world rightly in the pattern of correspondence of words with things in the world or state of affairs.

However, Wittgenstein's thought on language underwent a radical change to what is popularly known as the New or Later Wittgenstein. In this new phase, Wittgenstein saw that language has many functions besides simply 'picturing" objects. Language, he maintained, always functions in a context and therefore has many purposes as 
there are contexts. Words, Wittgenstein now held, are like "tools in a tool box; there is a harmmer, pliers, a saw, a screwdriver, a rule, a glue-pot, nails and screws - The function of words is as diverse as the functions of these object" (Stumpf,1977:446).

It is incontrovertible, from the above exposition of the purifying effect of philosophical analysis on thought, language and communication that philosophy is not just a mere convenient ally but a necessary ally to language and communication of meaning and the use of the latter to further man's quest for higher civilization and truth. The next section of this paper explores this.

\section{Philosophy, Language and Truth in Pursuit of Social Praxis}

Philosophy, language and truth are in inseparable natural union towards man's yearning for crisis-free social praxis since the dawn of history. Philosophy in its pristine mission seeks to understand the world as a dynamic unity. This is called the first order Philosophy. Philosophy, among other tools, uses conceptual analysis in the quest to understand the world. Philosophy in its department of conceptual analysis is seen as the second-order philosophy. However, I share the regret of Bryan Magee (from whom I borrowed the foregoing classification of philosophy) that the second-order philosophy was between the 1950s and 1960s misconcievedly imposed as the sole philosophy by the analytic movement.

Whether philosophy is seen in its first-order or second order perspectives or both, it plays an incisive role in language development (through concept evolution and concept analysis) which complements man's identity as a rational being who must, however hard it may be, cut his path to meaning and truth. Philosophy, by its logical purification of our concepts towards precise reference impacts positively 
on our cultural repertoire. Concepts understood as inarticulate bundles of personal intuitions and lived experiences constitute the fabrics of any culture. And culture itself is preserved and transmitted in language. The upshot is that the philosopher's improvement of our concepts enriches our culture which in turn enriches our language in the sense that the latter achieves larger cultural contents which may be scientific knowledge, the arts, institutional forms and practices etc.

This rigorous dynamism that bonds philosophy, concepts, culture and language in a generative rhythm has led philosophers and language scholars into the debate whether language is culture dependent or vice versa. Whatever is the result of such debate, our age has gone beyond seeing language as merely picturing external existent facts or objects.

It was this development that made the American pragmatist, W.V.O Quine to begin to see different endeavours as merely dependent on linguistic frameworks. He holds under his technical concept of "ontological relativity" that there are as many linguistic frameworks as there are different ways of organizing the data of experience. For example, there is the language of sense data, which is a different linguistic framework from physicalistic language. While the former talks about sense impressions, the later talks about physical objects. Science also has its own linguistic framework, where we talk about "mass" "energy" "force", "electromagnetic field", "gravity", in geometry there are objects like points, curves surface and solids. In mathematics, we have objects like "numbers", "classes," infinitesmals", "formulars" "sets" "functions" etc. In logic, there are different properties like "validity", "consistency" "truth value" "implications", "necessity", etc. All these, Quine 
maintains, are different linguistic frameworks that exist (Ozumba, 2002: 61-62).

On the other hand, Benjamin Whorf in his famous theory known as "Whorf hypothesis", holds that our conceptual scheme is determined by our language.

In any case, the rigorous dynamism that bonds philosophy, concepts, culture and language in a generative rhythm as discussed in the foregoing expressed itself in ways other than the creative tension between language and culture. This rigorous dynamism constitutes and delineates for a people their range of consciousness of truth, their ontology, what there is. In this way, philosophy contributes to formulate and present a people's objective consciousness (their culture) which not only describes their truth but also determine their social praxis.

It is this obvious and unbreakable link between philosophy and social praxis that has inspired philosophy to seek to clear our heads of mental rubbish and free us from linguistic obfuscation through conceptual analysis geared towards clarification of meaning. What is more, the close relationship that exists between logical analysis of our language and the linguistic efficiency thus attained makes them indispensable instruments of meaningful communication in the pursuit of social praxis. Where there is difficulty in the logical and linguistic links there is equally difficulty in achieving unified and purposeful social praxis. This difficulty could manifest in different areas between individuals and groups, between individuals, between groups and groups and even between nations and nations.

Since no serious meaningful and purposeful unified social praxis can be carried out without a common logical, linguistic and cultural concepts (which constitute the people's Weltanschauung), it becomes imperative to continue to 
improve our social praxis by continually enriching our concepts by critical analysis.

\section{Conclusion}

This essay is undoubtedly a positive reactions to Wittgenstein's thesis that "what can be said can be said clearly". Much mental and verbal rubbish is piled up when our thoughts and concepts are not analyzed and clarified for their literal significance or meaning. Much of the woolly thinking and irrational practices of our contemporary society would be drastically reduced if a regime of conceptual and linguistic sanity is maintained as recommended by Wittgenstein's thesis above.

Philosophical analysis and clarification of our thought and concepts as mediated by language reveal the logical and practical consequences of our thought and concepts and are therefore necessary components of personal development. It is an exercise that should be pursued for what it is worth. Every social endeavor will collapse the very moment language as a medium of shared meaning breaks down. The inextricability of thought, concept and language has produced two results in the philosophical world. Most analytic philosophers believe that philosophical problems are problems of language and hoped that by logical analysis of our concepts the philosophical problems will be dissolved if not resolved. On the other hand, philosophers who are not so inclined and who held the first and second order concerns of philosophy creatively together maintain that conceptual analysis is a sure route to understand and interpret a people's weltanschauung since concepts are the repositories of a people's cultural beliefs and practices.

The upshot is that whether philosophical problems are dissolved or resolved, much hangs on language as the medium of shared meaning. This is why philosophers have 
remained concerned with analysis and clarification of words, concepts and the way we employ language to communicate them. What is more, such conceptual and linguistic analysis impact positively on a peoples culture which in turn determine their social praxis.

\section{References}

Bowie, G. Lee, Michaels, Maredith W. and Solomon, Robert C. Twenty Questions: An Introduction to Philosophy $4^{\text {th }}$ edn. Harcourt College Publishers New York, 2000.

Christian, James. Philosophy: An introduction to the Art of Wondering. London: Word Sworth. 2003.

Dukor, Maduabuchi. "The Relevance of Philosophy and the Cooperate World: The Problem of Management Ethics" in Pantaleon Iroegbu and Anthony Echekueude eds. Kpim of Morality: Ethics-General, Special and Professional, Ibadan:Heinemann Educational Books Nig PIc., 2005.

Ijoma, Chukwuma P. "Communication, Language and the Arts" in LT.K. Egonu, African Perspectives in World Culture. Owerri:Vivians and Vivians Publishers, 1988.

Ozumba, G.O. Introduction to Philosophy of Language, Ibadan:Hope Publications 2004.

Plato. The last Days of Socrates. London: Penguin Books. 1954.

Popper, Karl. Conjunctions and Refutations. London: Routledge and Kegan Paul, 1963.

Russell, Bertrand. The Problems of Philosophy 2nd edn. London: Oxford Press. 1912,

Stumpf, Samuel Enoch. Philosophy: History and Problems, London: McGraw- Hill Inc. 1977. 
Wiredu, Kwesi. Conceptual Decolonisation in African Philosophy, Ibadan: Hope Publications, 1995

*Dr. Ifechukwu J. Ndianaefoo is of the Department of Philosophy, Nnamdi Azikiwe University, Awka. 